\title{
DAS HERZ DER WELT
}

Zum 100. Todestag von Joseph von Eichendorff am 26. November 1957

Christine Schodrok, Bonn.

Wer ist dieser Mensch, auf dessen Dichterwort sich noch hundert Jahre nach seinem Tode die moderne Welt besinnt? Um das Geheimnis seiner Poesie zu ergründen, möge man sich der Worte aus seinem Roman "Dichter und ihre Gesellen" erinnern: "Wer einen Dichter recht verstehen will, mup seine Heimat kennen. Auf ihre stillen Plätze ist der Grundton gebannt, der dann durch alle seine Bücher wie ein unaussprechliches Heimweh fortklingt. Auf keinen trifft dieses Bekenntnis besser zu, als auf Joseph von Eichendorff selbst. Am 10. März 1788 auf Schlo $\beta$ Lubowitz bei Ratibor geboren, wird Oberschlesien, das Land zwischen Preußen und Oesterreich mit seinem unerme $\beta$ lichen Wäldern voll wundersamer Sagen, Märchen und verwunschenen Seen, mit sanften Hügelketten und wogenden Aehrenfeldern, mit alten Gutshöfen, Burgen und Schlössern, mit wohlhabenden Städten und einer schon damals geschäftigen Industrie, mit Kirchen und Kapellen in farbenfrohem Barock der Erde und dem Himmel gleichermaßen verbunden, zur Grundmelodie seiner Dichtung.

Zusammen mit seinem älteren Bruder Wilhelm besuchte er von 1801 bis 1805 das Matthias-Gymnasium in Breslau und bis 1803 zum Studium der Rechts-und Staatswissenschaft Halle und Heidelberg, wo er erstmalig mit dem Kreis de: deutschen Romantiker, die damals einen leidenschaftlichen Kampf gegen die Ideen der reinen Verstandeslehre führten, in Berührung kam. Während der Studienjahre unternahmen die beiden Brüder Reisen in den Harz, nach Hamburg, Lübeck, Paris und Berlin. Dort begann der achtzehnjährige 
Joseph seinen ersten Roman "Ahnung und Gegenwart" zu schreiben, er vollendete ihn als Zweiundzwanzigjähriger in Wien. Hier, in der glanzvollen Kaiserstadt an der Donau, mit der den Schlesier zeitlebens eine herzliche Liebe verband, beschlo $\beta$ er seine Studien mit dem gro $\beta$ en Staatsexamen.

Sein bürgerliches Leben, das er als preu $\beta$ ischer Beamter in Breslau, Danzig, Königsberg und Berlin führte, war von strenger Pflichterfüllung und Lauterkeit getragen. Als Beauftragter des preußischen Kultusministeriums setzte er sich mit vollem Erfolg für die Wiederherstellung des Schlosses der deutschen Ordensritter - der Marienburg - und des Kölner Domes ein. 1844 trat er auf eigenen Wunsch vorzeitig in den Ruhestand, "weil ich mein Gewissen und meine Ehre stets höher gehalten habe als meinen Magen." Es folgten schaffensfrohe Jahre in Danzig, Berlin, Cöthen und Dresden, bis die oberschlesische Heimat ihren Sohn zur letzten Heimkehr rief: in Neisse starb er am 26. November 1857. Nun war sein ewiges Heimweh gestillt. Seine Gedanken und Lieder aber tönen weiter durch die Zeiten und künden vom Reichtum eines einfältig liebenden Herzens und vom wahren Trost der Welt.

Auch seine Zeit war voll politischer Sensationen: er wurde ein Jahr vor der französischen Revolution geboren und starb neun Jahre nach der deutschen. Dazwischen gab es die napoleonischen Kriege, den Wiener Kongre $\beta$, politische und geistige Reformen, Restauration - den endgültigen Zerfall des heiligen römischen Reiches deutscher Nation. Die elterlichen Schlösser gingen ihm in diesen Wirren verloren, und nie verlie $\beta$ ihn das Heimweh nach dem "Jubelparadies" seiner Kindheit. Aber der Dichter wußte den Schmerz zu meistern: er lie $\beta$ die Heimat zur Kunst werden. Das verlorene Kinderland wurde ihm zum Symbol der verlorenen transzendenten Urheimat des Menschen und seine Poesie der goldene, der wundersamste Weg zwischen Erde und Himmel. Eichendorff schuf mit der poetischen Verklärung seines Heimatlandes jene eigentümlich deutsche Stimmungs- 
landschaft mit "Tälern weit und Höhen", dem Posthorn im stillen Wald, mit jubelndem Frühling, Nächten im Mondenschein, wo die Sterne funkeln, die Nachtigallen schlagen und die Brunnen verschlafen rauschen, mit alten Burgen, einsamen Kapellen, der klappernden Mühle im Tal und dem ewigen Sonntag im Gemüt.

Man nennt Joseph von Eichendorff den "ietzten Ritter der Romantik". Gewi $\beta$, seine dichterische Leistung beeinflu $\beta$ te Freundschaften mit den Häuptern der romantischen Schule. In Halle waren es der Philologe F. A. Wolf, der Theologe Schleiermacher und der norwegische Naturphilosoph Henrik Steffens. In Heidelberg kam er vor allem in enge Verbindung mit Joseph Görres, Achim von Arnim, Clemens Brentano und den Brüdern Grimm. In Berlin traf er' auf Fichte, Heinrich von Kleist und den Nationalökonomen Adam Müller. In Wien fand er bei Friedrich und Dorothea Schlegel und deren Sohn Philipp Veit herzliche Aufnahme. Weiter hin gehörten zu seinem Freundeskreis u. a. Friedrich und Karolini de la Motte-Fouqué, Luise Hensel, Paul Heyse, Theodor Körner, Novalis, Adalbert Stifter und Ludwig Tieck. Während jedoch die Kunst der Romantiker sich oft in zielloser Erdensehnsucht verströmt, rettet und bewahrt Eichendorff das erdgebundene Welterleben, indem er es in das himmlische Reich hinüberträgt. Auch er spricht von der "keinem Dichter fremden dämonischen Gewalt", der Schlesier aber überwindet sie mit der geradezu kindlich selbstverständlichen Gewi $\beta$ heit, in der ewigen Heimat geborgen zu sein. Gleich einer Pilgrimschaft zu Gottes ewigem Frieden bewegt sich der Rhythmus seines Dichtens aus der Enge in die unendliche Landschaft, die wir meinen, wenn wir von deutscher Seele sprechen. So erscheint er uns wie ein Sänger, der vom Himmel kommt und uns die Freude aller Jugend bringt: die Reinheit des Gemütes, den frohen Sinn und die stille Wehmut.

Manche seiner Gedichte sind zu Volksliedern geworden, und die Krone aller seiner Novellen, "Aus dem Leben eines 
Taugenichts", ist bis heute ein in aller Welt geschätztes Stück deutscher Meisterpoesie. Nur scheinbar ist dieser Taugenichts ein nichtsnutziger, leichtsinniger Kerl, er hat vielmehr einen leichten Sinn, mit dem er den Philistern und Pharisäern eine Nase drehen möchte, wobei er in der Welt voll Gram und Glücke den lieben Gott nur walten läpt.

Jedoch "nicht Träume sind's und leere Wahngesichte, was von dem Volk den Dichter unterscheidet. Was er inbrünstig bildet, liebt und leidet, es ist des Lebens wahrhafte Geschichte". So zeigen die vielfältigen historischen, literarhistorischen, politischen und biographischen Schriften, da $\beta$ der Romantiker Eichendorff den realen Tatsachen des Lebens diszipliniert gegenüberstand und sich ernsthaft mit der Zeit und ihren Problemen auseinandersetzte, um mitzuhelfen, seinem Volk den rechteñ Weg zu weisen. Er verachtet die Dichter mit den "Taubenherzen", die in einer nur erträumten Welt "mit weinerlichen Sonetten die schöne alte Zeit zurückwinseln wollen". Die Kritik an manchen schwankenden Gestalten aus den ästhetisch-literarischen Salons seiner Zeit ist ein wesentlicher Bestandteil seiner dichterischen Aussage. "Wer in der Not nichts mag als Lauten rühren, des Hand dereinst wächst mahnend aus dem Grabe:" Hier zeigt sich jene Synthese zwischen dem Ernst des Lebens und der Fröhlichkeit des Herzens, die aus Eichendorffs Gesamterscheinung nicht fortgedacht werden kann. Der Dichter habe die hohe Mission, in der wild bewegten Welt, wo die Menschen ängstlich nach ihrem Retter schauen, das in allen Dingen schlafende Wort zu wecken, um somit kühn den Friedensbogen aus allem Wirrsal ins ewig Unveränderliche zu schlagen.

"Der Dichter kann nicht verarmen:

Wenn alles um ihn her zerfällt, Hebt ihn ein göttliches Erbarmen Der Dichter ist das Herz der Welt." 